\title{
The Practice of Pharmacy Infection Control by Pharmacists in Saudi Arabia
}

\section{Yousef Ahmed Alomi*, (D) BSC. Pharm, MSc. Clin Pharm, BCPS, BCNSP, DiBA, $\mathrm{CDE}$, Critical Care Clinical Pharmacists, TPN Clinical Pharmacist, Freelancer Business Planner, Content Editor, and Data Analyst, Riyadh, SAUDI ARABIA.}

Ghudair Tashan Alanazi, BSC

Pharm, Pharm.D, MSc. Clin Pharm, Diploma of Epid. Critical care clinical pharmacist, Internal medicine clinical pharmacist MOH, Hafrbatin, SAUDI ARABIA.

Ban Abdullah Aldosary, Bsc. Pharm Pharmaceutical Care Department, Al-Amel Mental City, Ministry of Health, Riyadh, SAUDI ARABIA.

Hussa Mubarak Muwainea, Prince Sultan Military Medical City, Riyadh, SAUDI ARABIA.

Razan Alshehri, College of Pharmacy, Taif University, Tail, SAUDI ARABIA.

\section{Correspondence:}

Dr. Yousef Ahmed Alomi, Bsc. Pharm, Msc. Clin pharm, BCPS, BCNSP, DiBA, CDE Critical Care Clinical Pharmacists, TPN Clinical Pharmacist, Freelancer Business Planner, Content Editor and Data Analyst, P.O.BOX 100, Riyadh 11392, Riyadh, SAUDI ARABIA.

Phone no: +966 504417712

E-mail:yalomi@gmail.com

Received: 01-02-2021;

Accepted: 17-05-2021;

Copyright: $\odot$ the author(s), publisher and licensee International Journal of Pharmacology and Clinical Sciences. This is an open-access article distributed under the terms of the Creative Commons

Attribution Non-Commercial License, which permits unrestricted non-commercial use, distribution, and reproduction in any medium, provided the original work is properly cited.

This is an open access article distributed under the terms of the Creative Commons AttributionNonCommercial-ShareAlike 4.0 License

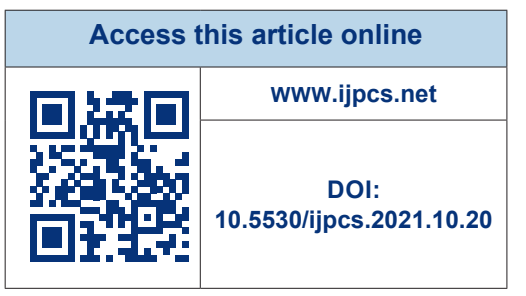

\begin{abstract}
Objectives: In this study, we aimed to illustrate the practice of pharmacy infection control by pharmacists in the Kingdom of Saudi Arabia. Methods: In this crosssectional study, we aimed to assess the practice of pharmacy infection control by pharmacists in Saudi Arabia. We used a self-reported electronic survey questionnaire and distributed it to pharmacists from interns to consultants and specialists in Saudi Arabia. The survey collected demographic information of the pharmacists and about the implemented pharmacy infection control practices. The practice of pharmacy infection control and pharmacy infection control responsibilities among the types of healthcare professionals. We used 5-point Likert response scale system with close-ended questions to obtain responses. The data were collected through the Survey Monkey system and analyzed with Statistical Package of Social Sciences (SPSS), Jeffery's Amazing Statistics Program (JASP), and Microsoft Excel (version 16) software. Results: A total of 435 pharmacists responded to the questionnaire. Of them, one-quarter belonged to the central region $(97(22.35 \%)$ ), followed by the northern region $(92(21.2 \%))$, and there were no statistically significant differences between the provinces $(p=0.637)$. Most of the responders were from a community pharmacy $(81(18.62 \%))$, Ministry of Health $(\mathrm{MOH})$ hospital $(69(15.86 \%))$, and military hospitals (49 $(11.26 \%))$, with statistically significant differences between working sites $(p=0.000)$. Moreover, $212(48.96 \%)$ were female, while 221 (51.04\%) were male, with non-statistically significant among the areas $(p=0.665)$. Most of the responders were in the age group of $24-30$ years $(151(34.87 \%))$ and $36-40$ years $(101(23.33 \%))$ with statistically significant differences between all age groups $(p=0.000)$. The average score of the elements related to the implementation of pharmacy infection control practices was 3.07, with high scores obtained for the aspect "the vision of pharmacy infection control" (3.79) and "mission of pharmacy infection control" (3.55). In contrast, the lowest score was obtained for the element "competition in infection control pharmacy" (2.51) and infection control pharmacy and quality management (2.65). The average score for the element implementation of pharmacy infection control practice was 3.47 , with high scores obtained for the element "the pharmacist share in infection control committee" (4.37) and "the pharmacist was always a staff member of infection control or pharmacy departments" 3.84. In contrast, the lowest score was obtained for the element attending several courses or workshops about pharmacy infection control (3.17). The scores for the single-test reliability analysis of McDonald's $\omega$ was 922, Cronbach's a was0.919, Gutmann's $\lambda 2$ was 0.930, Gutmann's $\lambda 6$ was 0.973 , and Greater Lower Bound was 0.990. Conclusion: In this study, pharmacists' practice of pharmacy infection control was found to be inadequate in Saudi Arabia. Therefore, implementing infection control in pharmacy practice is required to prevent drug-related infection control problems. In addition, we recommend improving the infection control practice in pharmacy services in Saudi Arabia.

Key words: Practice, Pharmacy, Infection, Control, Saudi Arabia.
\end{abstract}

\section{INTRODUCTION}

Infection control is an essential concept for healthcare professionals, including pharmacists. ${ }^{[1-6]}$ The pharmacist needs to prevent the infection before or during dispensing of medications. The pharmacist needs to follow hand hygiene regularly to avoid any transmission of infection. ${ }^{[7]}$ Moreover, infection control needs to be periodically practiced at different pharmacy services, including inpatient pharmacy, outpatient pharmacy, and clinical pharmacy services..$^{[1-6]}$ It is required for the pharmacy environment, workplaces, equipment, and pharmacy staff. Pharmacists distribute and dispense hand sanitizer and disinfectant solutions to various healthcare sections in their organization. There are different standards of infection control for medical and nursing care. ${ }^{[1-6]}$ However, only a few studies have talked about complete pharmacy infection control programs or guidelines, and some have focused their research on one type of pharmacy service during the mass gathering. ${ }^{[8-13]}$ Various practices of pharmacy infection control should be addressed such as vision, mission, strategic plan, and policies and procedures in addition to the competency of pharmacy infection control, surveillance-monitoring, immunization for pharmacy staff and trainees, and medications storage. ${ }^{[1-6]}$ However, to the best of our knowledge, there are no studies, especially 
on pharmacy practice of pharmacy infection control. ${ }^{[14-16]}$ Therefore, in this study, we aimed to assess the practice of pharmacy infection control in the Kingdom of Saudi Arabia.

\section{METHODS}

It was a cross-sectional study that explored the practice of pharmacy infection control during pharmaceutical care in Saudi Arabia. We used an electronic and self-reported survey questionnaire and distributed it to pharmacists from interns to consultants and all pharmacy specialties in Saudi Arabia. All non-pharmacists, students, and incomplete surveys were excluded from the study. The survey collected demographic information of the pharmacists and data regarding the practice and implementation of pharmacy infection control and pharmacy infection control (to authorities) responsibility of types of healthcare professionals. We used a 5-point Likert response scale system with close-ended questions to obtain responses. Based on the previous literature with unlimited population size, the sample was calculated for this crosssectional study with a population percentage of $50 \%$, the confidence level of $95 \%$, a $z$ score of 1.96 , and a margin of error of 5-6.5\%, and drop-out rate of $10 \%$. Thus, the calculated sample size was around 251-432 with a power of study of $80 \% .{ }^{[17-19]}$ The response rate required for the calculated sample size was at least $60-70 \%{ }^{[19,20]}$ The survey was distributed through social media such as WhatsApp and Telegram apps. In addition, a reminder message was sent once every $2-3$ weeks. The expert reviewers and pilot testing validated the survey data. Moreover, the test of reliability Gutmann's $\lambda 6$, Gutmann's $\lambda 2$, McDonald's $\omega$, and Cronbach's a were calculated. The data were analyzed through the Survey Monkey system, and we used Statistical Package of Social Sciences (SPSS), Jeffery's Amazing Statistics Program (JASP), and Microsoft Excel (version 16) software for data analysis. We performed descriptive and frequency analysis, the goodness of fit analysis, correlation analysis, and inferential analysis of factors affecting medication safety practice. The STROBE (Strengthening the reporting of observational studies in epidemiology statement: guidelines for reporting observational studies) guided the reporting of the results of this study. ${ }^{[21-23]}$

\section{RESULTS}

A total of 435 pharmacists responded to the survey. Of them, one-quarter were from the central region $(97(22.35 \%))$ and northern area $(92(21.2 \%))$, and there were no statistically significant differences between the provinces $(p=0.637)$. Of those, most of the responders were from a community pharmacy (81 (18.62\%)), Ministry of Health (MOH) hospitals $(69(15.86 \%))$, and military hospitals (49 (11.26\%)), with statistically significant differences between worksites $(p=0.000)$. Of the total responders, 212 (48.96\%) were female, and $221(51.04 \%)$ were male, and there was no statistically significant difference between them $(p=0.665)$. Most of the responders were in the age group of $24-30$ years (151 (34.87\%)) followed by $36-40$ years $(101(23.33 \%))$, with statistically significant differences between all age groups $(p=0.000)$. Most of the pharmacists were pharmacy staff (192 (44.55\%)) and pharmacy supervisors (104 (24.13\%)), with statistically significant differences between all levels of qualifications $(p=0.000)$. The majority of the responders held Bachelor in Pharmacy degree $(281(64.75 \%))$, Master in Pharmacy degree (94 (21.66\%)), and Diploma in Pharmacy (90 (20.74\%)). Most pharmacists have work experience of 7-9 years (117 $(27.08 \%))$ and $4-6$ years $(116(26.85 \%))$, with statistically significant differences between all levels of experience $(p=0.000)$. Almost one-fifth of the pharmacists practiced at the clinical pharmacy $(62(18.08 \%))$, outpatient pharmacy (61 (17.78\%)), and inpatient pharmacy (555 (16.03\%)), with statistically significant differences between all sites of pharmacy practice $(p=0.000)$. There is a strong positive correlation between age (years) and years of experience in pharmacy career based on Kendall's tau_b (0.576) and Spearman's rho (0.701), with statistically significant differences between them $(p<0.001)$ (Tables 1 and 2). The average score for the implemented items for pharmacy infection control practice was 3.07, with high scores obtained for the elements "the vision of pharmacy infection control" (3.79), "mission of pharmacy infection control" (3.55), "infection control pharmacy and drug quality reporting systems" (3.37), and "the strategic plan of pharmacy infection control" (3.35). In contrast, low scores were obtained for the elements "infection control pharmacy competency" (2.51), "Infection control pharmacy and quality management" (2.65), and "policies and procedure of pharmacy infection control" (2.77), with significant statistical differences between all responses $(p=0.000)$ (Table 3$)$. The average score for the elements of pharmacy infection control practice implementation was 3.47, with high scores obtained for the elements "the pharmacist share in infection control committee" (4.37) and "the pharmacist was always a staff member of infection control or pharmacy departments" (3.84). In contrast, the lowest score was obtained for the element "the attendance of several courses or workshops about pharmacy infection control" (3.17) and "there are electronic pharmacy infection control performances" (3.34), with a statistically significant difference between all the answers in all aspects in pharmacy practice $(p=0.000)$ (Table 4). The highest scores of pharmacy infection control (to authorities) were obtained for the element "the responsibility of types of healthcare professionals was an infection control pharmacist" (3.95) and "infection control doctors" (3.94). In contrast, the lowest score was obtained for the element "infectious diseases doctors" (3.29) and "infection control nurses" (3.37), with statistically significant differences between the responses $(p=0.000)$ (Table 5). The score for the single-test reliability analysis of McDonald's $\omega$ was 922, Cronbach's awas 0.919 , Gutmann's $\lambda 2$ was 0.930 , Gutmann's $\lambda 6$ was 0.973 , and Greater Lower Bound was 0.990 .

\section{Factors influencing the pharmacist's practice of pharmacy infection control}

In this study, we performed independent samples Kruskal-Wallis test and the Bonferroni correction for multiple tests to obtain adjusted significant values, which are as follows. The factors that might affect pharmacists' practice of pharmacy infection control include location, worksite, gender, age, practice area, current position held, and years of experience. Gender alone did not affect the knowledge of storage, with a non-statistically significant difference between males and females $(p>0.05)$. Five locations affected the practice of pharmacy infection control by pharmacists. The western region showed the lowest scores (2.8144), with a statistically significant difference between all regions $(p=0.000)$. Fourteen levels of the working site showed low scores, in which case private hospitals obtained the lowest score (2.4963), with a statistically significant difference between them $(p=0.000)$. Six different age groups affected the practice of pharmacy infection control. The lowest score (2.7477) was obtained for the age group of 24-30 years, with a statistically significant difference between all age groups $(p=0.000)$. Twelve practice areas showed a low score (2.4762), and the area of pharmaceutical companies showed a statistically significant difference $(p=0.000)$. Five career positions affected the practice of pharmacy infection control, with the lowest score (2.7767) obtained for the intern position, which was statistically significant $(p=0.013)$. Six levels of years of experience affected the practice of pharmacy infection control. The lowest score (2.7478) was obtained for $<1$ year of experience, followed by $1-3$ years of experience (2.7578) and $>12$ years of experience (2.7474), and the differences were statistically 


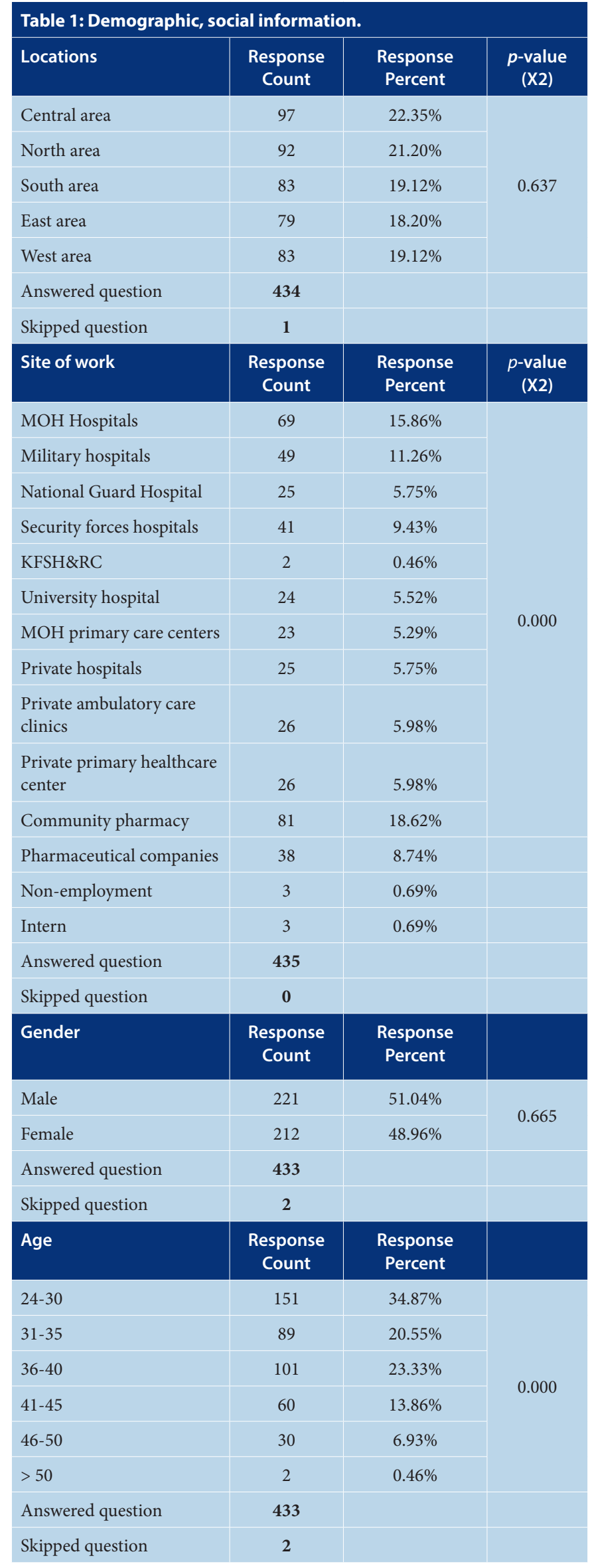

\begin{tabular}{|c|c|c|c|}
\hline Pharmacist's Qualifications & $\begin{array}{l}\text { Response } \\
\text { Count }\end{array}$ & $\begin{array}{c}\text { Response } \\
\text { Percent }\end{array}$ & $\begin{array}{l}p \text {-value } \\
(\mathrm{X} 2)\end{array}$ \\
\hline Diploma in Pharmacy & 1 & $0.23 \%$ & \\
\hline Bachelor in pharmacy & 281 & $64.75 \%$ & \\
\hline Master & 94 & $21.66 \%$ & \\
\hline Pharm D & 90 & $20.74 \%$ & \\
\hline $\mathrm{Ph} . \mathrm{D}$ & 12 & $2.76 \%$ & \\
\hline PGY 1 & 9 & $2.07 \%$ & \\
\hline PGY 2 & 15 & $3.46 \%$ & \\
\hline PGY 3 & 7 & $1.61 \%$ & \\
\hline Fellowship & 4 & $0.92 \%$ & \\
\hline Other (please specify) & 2 & $0.46 \%$ & \\
\hline Answered question & 434 & & \\
\hline Skipped question & 1 & & \\
\hline Position Held & $\begin{array}{l}\text { Response } \\
\text { Count }\end{array}$ & $\begin{array}{c}\text { Response } \\
\text { Percent }\end{array}$ & \\
\hline Director of Pharmacy & 46 & $10.67 \%$ & \multirow{4}{*}{0.000} \\
\hline Assistant Director of Pharmacy & 51 & $11.83 \%$ & \\
\hline Supervisor & 104 & $24.13 \%$ & \\
\hline Pharmacy staff & 192 & $44.55 \%$ & \\
\hline Intern & 38 & $8.82 \%$ & \\
\hline Answered question & 431 & & \\
\hline Skipped question & 4 & & \\
\hline $\begin{array}{l}\text { Years of experience at Dentists } \\
\text { career }\end{array}$ & $\begin{array}{l}\text { Response } \\
\text { Count }\end{array}$ & $\begin{array}{c}\text { Response } \\
\text { Percent }\end{array}$ & \\
\hline Less than one year & 69 & $15.97 \%$ & \multirow{8}{*}{0.000} \\
\hline $1-3$ & 83 & $19.21 \%$ & \\
\hline $4-6$ & 116 & $26.85 \%$ & \\
\hline $7-9$ & 117 & $27.08 \%$ & \\
\hline $10-12$ & 25 & $5.79 \%$ & \\
\hline$>12$ & 22 & $5.09 \%$ & \\
\hline Answered question & 432 & & \\
\hline Skipped question & 3 & & \\
\hline Pharmacy practice & $\begin{array}{l}\text { Response } \\
\text { Count }\end{array}$ & $\begin{array}{c}\text { Response } \\
\text { Percent }\end{array}$ & \multirow{13}{*}{0.000} \\
\hline Pharmacy adminstration & 1 & $0.29 \%$ & \\
\hline Inpatient Pharmacy & 55 & $16.03 \%$ & \\
\hline Outpatient Pharmacy & 61 & $17.78 \%$ & \\
\hline Satellite Pharmacy & 17 & $4.96 \%$ & \\
\hline Narcotics and Controlled & 22 & $6.41 \%$ & \\
\hline Extemporaneous Preparation & 8 & $2.33 \%$ & \\
\hline Clinical Pharmacy & 62 & $18.08 \%$ & \\
\hline Inventory Control & 26 & $7.58 \%$ & \\
\hline Drug Information & 17 & $4.96 \%$ & \\
\hline IV admixture & 19 & $5.54 \%$ & \\
\hline Community pharmacy & 33 & $9.62 \%$ & \\
\hline Pharmaceutical companies & 22 & $6.41 \%$ & \\
\hline Answered question & 343 & & \\
\hline Skipped question & 92 & & \\
\hline
\end{tabular}


$\frac{9}{3}$

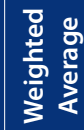

高

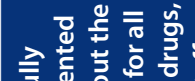

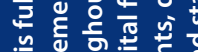

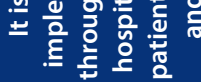

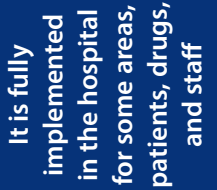
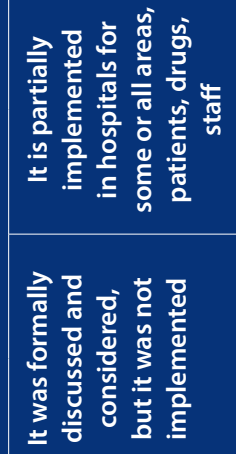

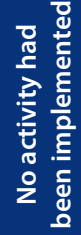

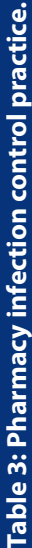

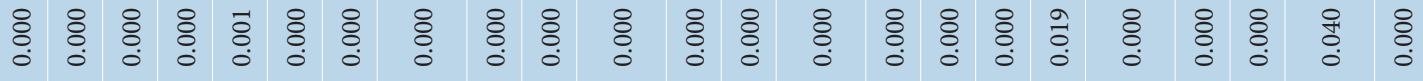

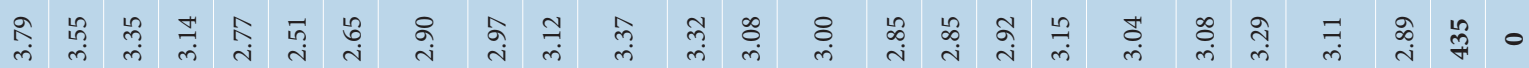

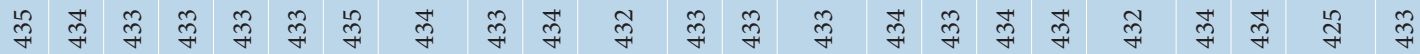

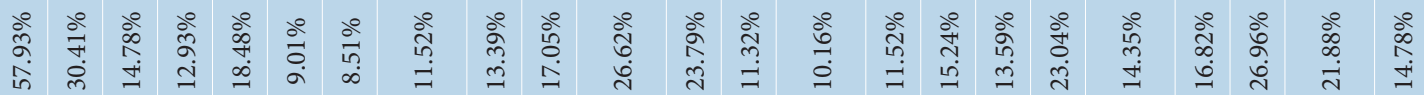
$\approx$ 苞点 学

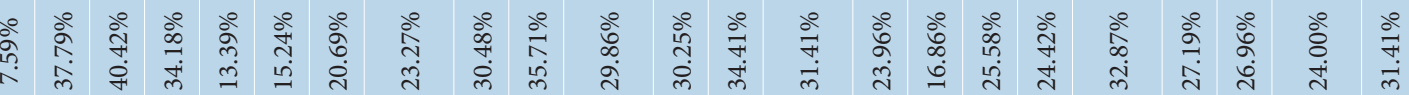

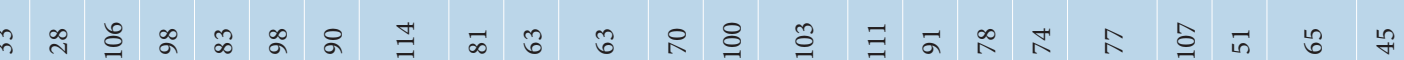

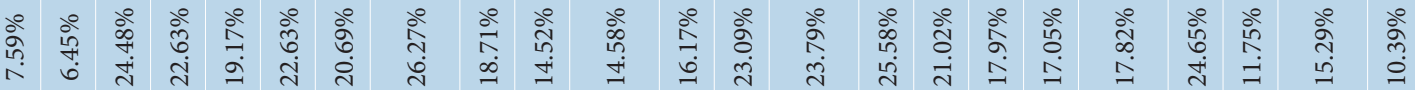
లి

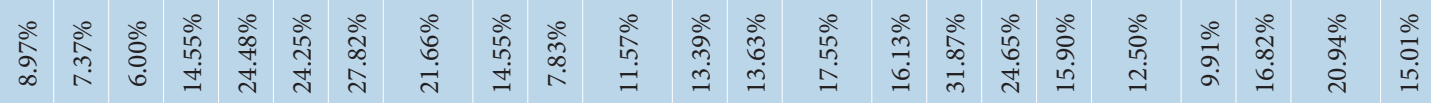

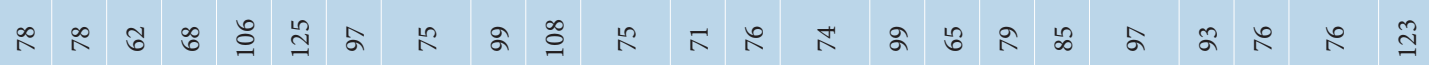

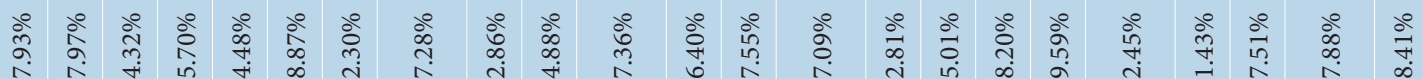

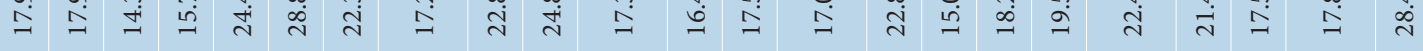

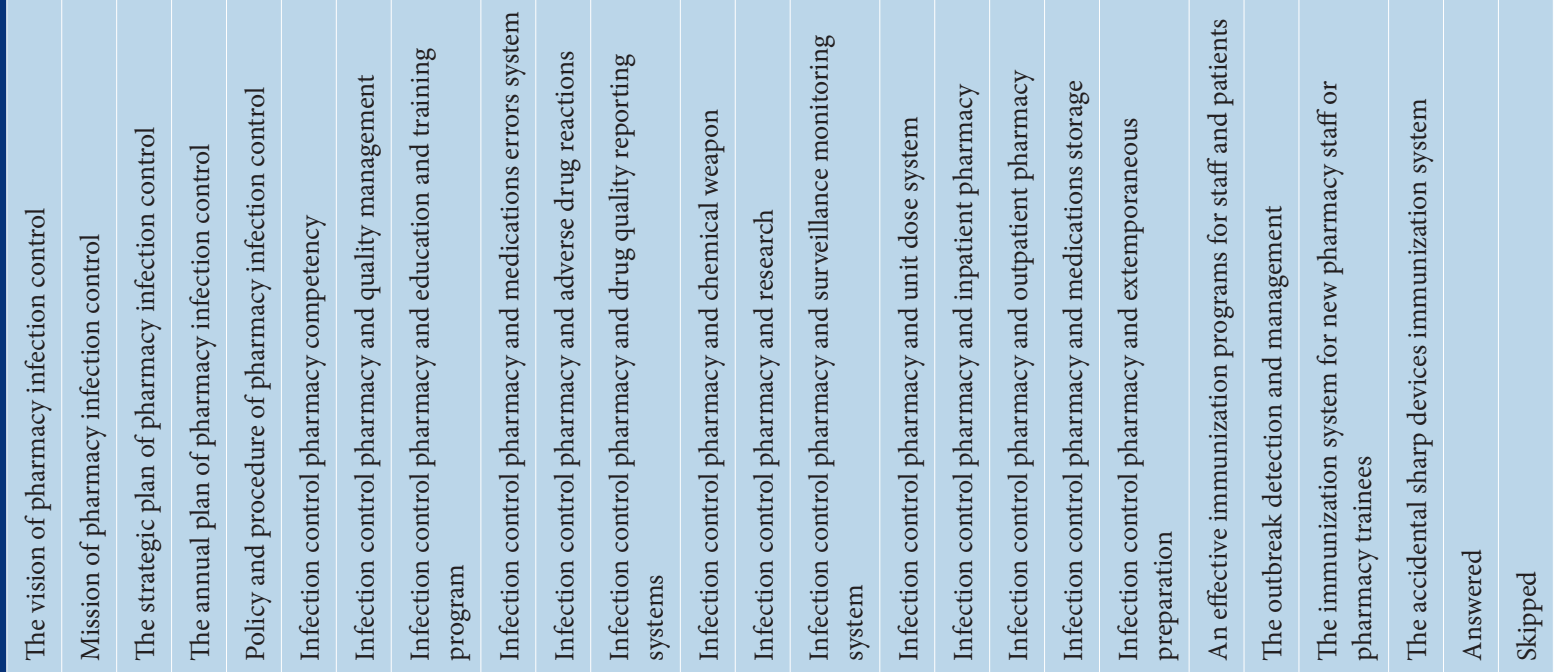




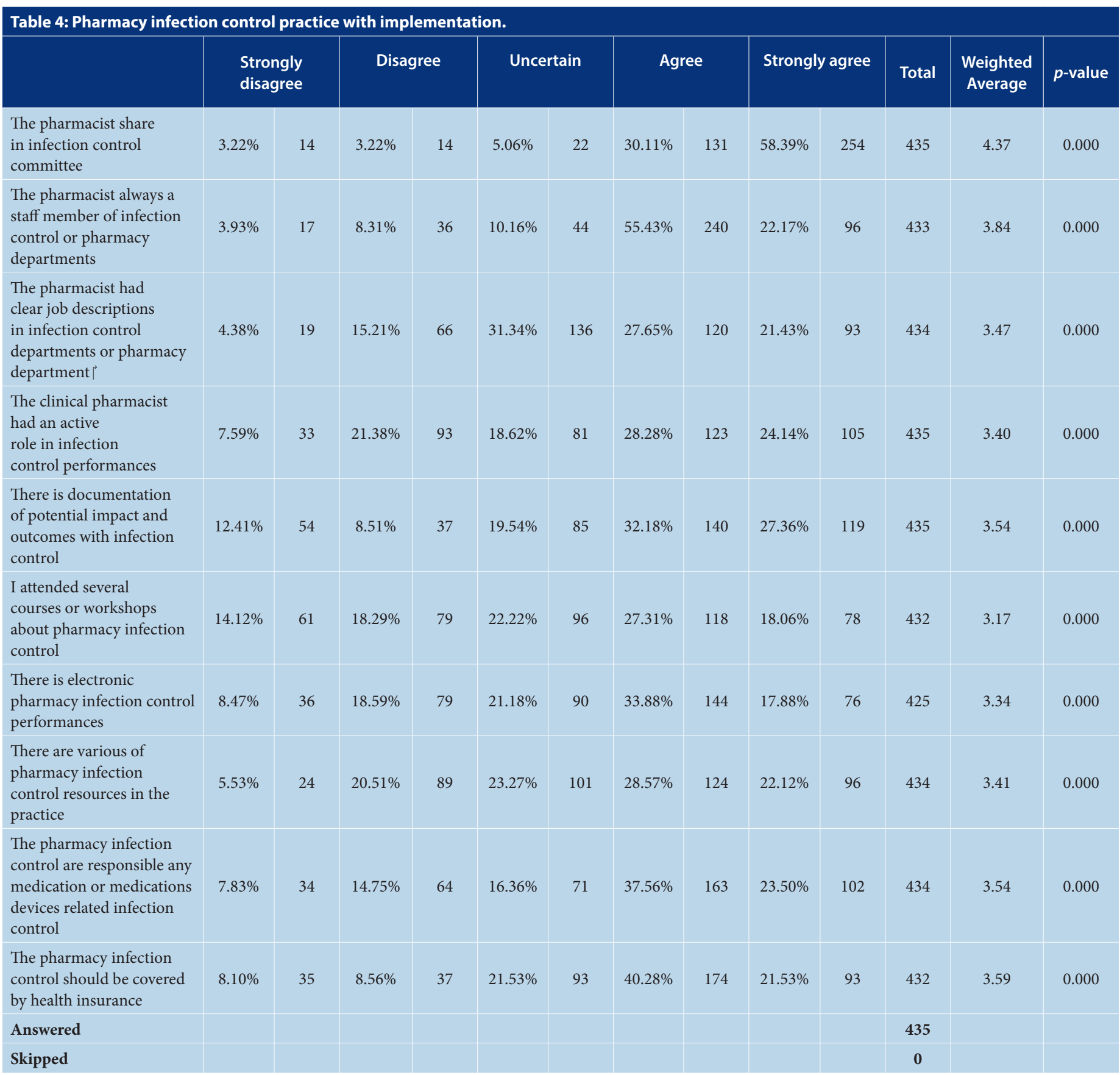

significant $(p=0.000)$. The relationship between the practice of pharmacy infection control and factors including location, worksite, age (years), gender, practice area, years of experience, and current position held. Multiple regression analysis revealed a weak relationship $(R=0.234$ with $p=0.001$ ) between pharmacy infection control practice and its factors. All factors showed non-significant differences $(p>0.05)$. However, a single factor (i.e., age) explained a $20.1 \%$ positive relationship to the pharmacy infection control knowledge variation, with a statistically significant difference $(p=0.014)$, which the Bootstrap model confirmed. The non-existence of multi-collinearity verified the relationship with the years of experiences factor with variance inflation factor (VIF) of 2.340 less than three or five ${ }^{[24-26]}$ (Table 6).

On the contrary, the factors were affecting the pharmacy infection control implementation. We adjusted the significant values using independent samples Kruskal-Wallis test and the Bonferroni correction for multiple tests. Various factors influenced the implementation of pharmacy infection control, including location, worksite, gender, age, practice area, current position held, and years of experience. Two factors (gender and practice area) did not affect the knowledge of storage with a nonstatistically significant difference $(p>0.05)$. Five locations affected the implementation of pharmacy infection control practice. The southern region showed the lowest scores (3.3759), with a statistically significant difference between the regions $(p=0.003)$. Fourteen groups of the worksite affected the implementation of pharmacy infection control, with the highest scores obtained for the university hospital (3.9708) and military 
hospital (3.8653), and the differences were statistically significant $(p=0.000)$. Six different age groups affected the practice of infection control implementation, and the lowest score (3.3547) was obtained for the age group of 31-35 years, with a statistically significant difference $(p=0.001)$. Five different current positions held affected the practice of infection control implementation, and the highest score (3.7485) was obtained for pharmacy staff, and the differences were statistically significant $(p=0.000)$. Six groups of work experiences affected the practice of infection control implementation, and the lowest score (3.3481) was obtained for 1-3 years of experience, with statistically significant differences between all age groups $(p=0.000)$. The relationship between pharmacy infection control implementation

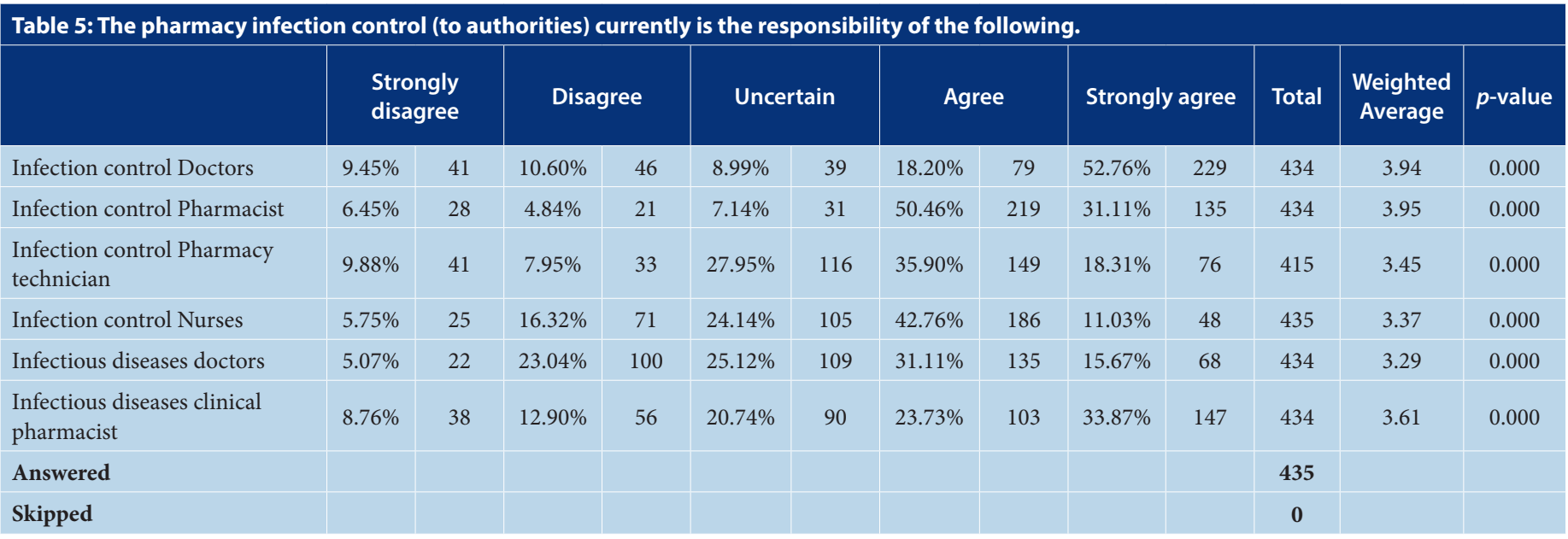

\begin{tabular}{|c|c|c|c|c|c|c|c|c|c|c|c|c|c|c|}
\hline \multirow{2}{*}{\multicolumn{2}{|c|}{ Model }} & \multirow[b]{2}{*}{ R } & \multirow[b]{2}{*}{$\begin{array}{c}R \\
\text { Square }\end{array}$} & \multirow[b]{2}{*}{ F } & \multirow[b]{2}{*}{ Sig. } & \multicolumn{2}{|c|}{$\begin{array}{l}\text { Unstandardized } \\
\text { Coefficients }\end{array}$} & \multirow{2}{*}{$\begin{array}{c}\text { Standardized } \\
\text { Coefficients } \\
\text { Beta }\end{array}$} & \multirow[b]{2}{*}{$t$} & \multirow[b]{2}{*}{ Sig. } & \multicolumn{2}{|c|}{$\begin{array}{c}95.0 \% \\
\text { Confidence } \\
\text { Interval for B }\end{array}$} & \multicolumn{2}{|c|}{$\begin{array}{l}\text { Collinearity } \\
\text { Statistics }\end{array}$} \\
\hline & & & & & & B & $\begin{array}{l}\text { Std. } \\
\text { Error }\end{array}$ & & & & $\begin{array}{l}\text { Lower } \\
\text { Bound }\end{array}$ & $\begin{array}{l}\text { Upper } \\
\text { Bound }\end{array}$ & Tolerance & VIF \\
\hline \multirow[t]{8}{*}{1} & (Constant) & \multirow[t]{8}{*}{$.234^{\mathrm{b}}$} & \multirow[t]{8}{*}{.055} & \multirow[t]{8}{*}{2.746} & \multirow[t]{8}{*}{$.009^{\mathrm{b}}$} & 2.327 & 0.385 & & 6.047 & 0.000 & 1.570 & 3.085 & & \\
\hline & Location & & & & & -0.027 & 0.035 & -0.041 & -0.754 & 0.451 & -0.096 & 0.043 & 0.954 & 1.048 \\
\hline & Site of work & & & & & 0.001 & 0.016 & 0.004 & 0.068 & 0.946 & -0.030 & 0.033 & 0.745 & 1.342 \\
\hline & Age (years) & & & & & 0.145 & 0.059 & 0.201 & 2.469 & 0.014 & 0.030 & 0.261 & 0.427 & 2.340 \\
\hline & Pharmacist gender & & & & & 0.200 & 0.108 & 0.105 & 1.860 & 0.064 & -0.012 & 0.412 & 0.893 & 1.120 \\
\hline & Practice area & & & & & 0.031 & 0.017 & 0.106 & 1.788 & 0.075 & -0.003 & 0.064 & 0.807 & 1.239 \\
\hline & Current Position & & & & & -0.008 & 0.053 & -0.009 & -0.143 & 0.886 & -0.112 & 0.097 & 0.709 & 1.410 \\
\hline & $\begin{array}{l}\text { Years of } \\
\text { experiences }\end{array}$ & & & & & 0.003 & 0.054 & 0.005 & 0.060 & 0.952 & -0.104 & 0.110 & 0.461 & 2.170 \\
\hline
\end{tabular}

a. Dependent Variable: Pharmacy infection control practice, Predictors b: (Constant), Location, Site of work, Age (years), Pharmacist gender, Practice area, years of experience, and current Position.

\begin{tabular}{|c|c|c|c|c|c|c|c|}
\hline \multicolumn{8}{|c|}{ Bootstrap for Coefficients } \\
\hline & \multirow[b]{3}{*}{ Model } & \multirow[b]{3}{*}{ B } & \multicolumn{5}{|c|}{ Bootstrap ${ }^{a}$} \\
\hline & & & \multirow[b]{2}{*}{ Bias } & \multirow[b]{2}{*}{ Std. Error } & \multirow[b]{2}{*}{ Sig. (2-tailed) } & \multicolumn{2}{|c|}{ 95\% Confidence Interval } \\
\hline & & & & & & Lower & Upper \\
\hline \multirow[t]{8}{*}{1} & (Constant) & 2.327 & -0.006 & 0.434 & 0.001 & 1.479 & 3.179 \\
\hline & Location & -0.027 & -0.001 & 0.040 & 0.502 & -0.110 & 0.050 \\
\hline & Site of work & 0.001 & 0.000 & 0.019 & 0.946 & -0.036 & 0.036 \\
\hline & Age (years) & 0.145 & -0.002 & 0.056 & 0.015 & 0.031 & 0.250 \\
\hline & Pharmacist gender & 0.200 & -0.005 & 0.110 & 0.069 & -0.021 & 0.405 \\
\hline & Practice area & 0.031 & 0.000 & 0.020 & 0.135 & -0.009 & 0.070 \\
\hline & Current Position & -0.008 & 0.001 & 0.053 & 0.876 & -0.106 & 0.099 \\
\hline & Years of experiences & 0.003 & 0.005 & 0.057 & 0.954 & -0.107 & 0.119 \\
\hline
\end{tabular}

a. Unless otherwise noted, bootstrap results are based on 1000 bootstrap samples 


\begin{tabular}{|c|c|c|c|c|c|c|c|c|c|c|c|c|c|c|}
\hline & \multirow[b]{2}{*}{ Model } & \multirow[b]{2}{*}{$\mathbf{R}$} & \multirow[b]{2}{*}{$\begin{array}{c}\mathbf{R} \\
\text { Square }\end{array}$} & \multirow[b]{2}{*}{$\mathbf{F}$} & \multirow[b]{2}{*}{ Sig. } & \multicolumn{2}{|c|}{$\begin{array}{l}\text { Unstandardized } \\
\text { Coefficients }\end{array}$} & \multirow{2}{*}{$\begin{array}{c}\begin{array}{c}\text { Standardized } \\
\text { Coefficients }\end{array} \\
\text { Beta }\end{array}$} & \multirow[b]{2}{*}{$\mathbf{t}$} & \multirow[b]{2}{*}{ Sig. } & \multicolumn{2}{|c|}{$\begin{array}{c}95.0 \% \\
\text { Confidence } \\
\text { Interval for B }\end{array}$} & \multicolumn{2}{|c|}{$\begin{array}{l}\text { Collinearity } \\
\text { Statistics }\end{array}$} \\
\hline & & & & & & B & $\begin{array}{l}\text { Std. } \\
\text { Error }\end{array}$ & & & & $\begin{array}{l}\text { Lower } \\
\text { Bound }\end{array}$ & $\begin{array}{l}\text { Upper } \\
\text { Bound }\end{array}$ & Tolerance & VIF \\
\hline \multirow[t]{8}{*}{1} & (Constant) & \multirow[t]{8}{*}{$.292^{\mathrm{b}}$} & \multirow[t]{8}{*}{.085} & \multirow[t]{8}{*}{4.424} & \multirow[t]{8}{*}{$.000^{\mathrm{b}}$} & 3.263 & 0.230 & & 14.183 & 0.000 & 2.810 & 3.716 & & \\
\hline & Location & & & & & -0.032 & 0.021 & -0.082 & -1.531 & 0.127 & -0.074 & 0.009 & 0.954 & 1.048 \\
\hline & Site of work & & & & & -0.011 & 0.010 & -0.071 & -1.169 & 0.243 & -0.030 & 0.008 & 0.745 & 1.342 \\
\hline & Age (years) & & & & & 0.063 & 0.035 & 0.143 & 1.781 & 0.076 & -0.007 & 0.132 & 0.427 & 2.340 \\
\hline & Pharmacist gender & & & & & -0.060 & 0.064 & -0.052 & -0.937 & 0.349 & -0.187 & 0.066 & 0.893 & 1.120 \\
\hline & Practice area & & & & & 0.002 & 0.010 & 0.014 & 0.242 & 0.809 & -0.018 & 0.023 & 0.807 & 1.239 \\
\hline & Current Position & & & & & 0.133 & 0.032 & 0.260 & 4.179 & 0.000 & 0.070 & 0.195 & 0.709 & 1.410 \\
\hline & $\begin{array}{l}\text { Years of } \\
\text { experiences }\end{array}$ & & & & & 0.000 & 0.033 & -0.001 & -0.014 & 0.989 & -0.064 & 0.063 & 0.461 & 2.170 \\
\hline
\end{tabular}

a. Dependent Variable: Pharmacy infection control implementation, Predictors ${ }^{\text {b: }}$ (Constant), Location, Site of work, Age (years), Pharmacist gender, Practice area, years of experience, and current Position

\begin{tabular}{|c|c|c|c|c|c|c|c|}
\hline & \multicolumn{7}{|c|}{ Bootstrap for Coefficients } \\
\hline & \multirow{2}{*}{ Model } & \multirow{2}{*}{ B } & \multicolumn{5}{|c|}{ Bootstrap ${ }^{a}$} \\
\hline & & & Bias & Std. Error & Sig. (2-tailed) & \multicolumn{2}{|c|}{ 95\% Confidence Interval } \\
\hline \multirow[t]{6}{*}{1} & (Constant) & 3.263 & 0.011 & 0.221 & 0.001 & 2.844 & 3.692 \\
\hline & Location & -0.032 & -0.001 & 0.021 & 0.119 & -0.074 & 0.008 \\
\hline & Pharmacist gender & -0.060 & -0.002 & 0.063 & 0.336 & -0.182 & 0.064 \\
\hline & Practice area & 0.002 & 0.000 & 0.010 & 0.815 & -0.018 & 0.023 \\
\hline & Current Position & 0.133 & -0.001 & 0.027 & 0.001 & 0.080 & 0.184 \\
\hline & Years of experiences & 0.000 & -0.002 & 0.036 & 0.994 & -0.072 & 0.066 \\
\hline
\end{tabular}

a. Unless otherwise noted, bootstrap results are based on 1000 bootstrap samples

and factors affecting it, including location, worksite, age (years), gender, practice area, years of experience, and current position held, was analyzed through a multiple regression model. According to the results, there was a weak relationship $(\mathrm{R}=0.292$ with $p=0.000)$ between pharmacy infection control practice and factors affecting it. All factors did not show significant differences $(p>0.05)$. However, a single factor (i.e., current position) explained $26 \%$ of the positive relationship in variation to the implementation of pharmacy infection control, with a statistically significant difference between them $(p=0.014)$. The non-existence of multi-collinearity verified the relationship with the years of experiences factor with variance inflation factor $(\mathrm{VIF}=1.410)$ less than three or five $e^{[24-26]}$ (Table 7).

\section{DISCUSSION}

The practice of pharmacy infection control is highly essential in the field of pharmacy. ${ }^{[1-6]}$ Various sections of the pharmacy section require infection control tools, which include the IV admixture, compounding sterile and non-sterile medications, and extemporaneous preparation in addition to the preparation and dispensing of medicines at inpatients and outpatient pharmacies. ${ }^{[7,27-29]}$ Therefore, exploring the pharmacy infection practice is highly suggested to resolve any defect. This study, with a validated and highly reliable survey of all types of site pharmacists in different regions with appropriate sample size, was found to be better than that of previous studies. ${ }^{[14-16]}$ It was mainly in terms of community pharmacies, MOH hospitals, and military healthcare organizations. In this study, there were non-significant differences in the number of male and female responders. The responders had obtained a Bachelor's degree in Pharmacy or Diploma in Pharmacy, and most of them practiced in various specialties and outpatient and inpatient pharmacies. Moreover, most respondents who had good work experience also practiced pharmacy infection control. Unfortunately, the pharmacy infection control practice by the respondents was inadequate. Most pharmacists had a vision; the mission of pharmacy infection control was expected, especially from common pharmacy practice. However, some essential practices have not been established, such as competency of the pharmacist, pharmacy infection control, or unclear policies and procedures, which lead to malpractice of pharmacy infection control. Moreover, pharmacists participated in the infection committee in this study and sometimes worked at the infection control department, similar to a previous study. ${ }^{[15]}$ However, education and training programs for pharmacy infection control were seldom practiced or were absent. Moreover, there are no available electronic pharmacy infection control activities. That was expected because it was a new program, and it will take time to become the electronic version. In this study, the pharmacists agreed that pharmacy infection control should be the responsibility of the department of pharmacy, followed by the medical doctors. 
In this study, various factors affected the practice of pharmacy infection control, such as the location of the pharmacist. Based on the location, the western region showed the lowest score for the practice of pharmacy infection control, which may be related to an inadequate approach to infection control practice and insufficient education and training provided during undergraduate and postgraduate courses. Other factors that might affect the practice of pharmacy infection control were practice areas. In this case, private hospitals revealed poorly trained pharmacists and inadequate policies and procedures of pharmacy infection control. In contrast, other governmental healthcare organizations showed a high score for infection control practice, such as university hospitals or King Faisal Specialist Hospital and Research Center (KFSHRC). In this study, young age, intern position, and less experience affected the practice of pharmacy infection control. Furthermore, the practice area also influenced the practice of infection control inside the pharmacy. Pharmaceutical companies emphasizing the administration offices might rarely implement or apply the infection control program inside the administration offices. Our results showed that only a single dependent factor (i.e., age) explained $20 \%$ of the positive response in the pharmacy infection control practice, which is expected because the pharmacy infection control needs experience in practice

On the contrary, some factors affected the pharmacy infection control implementation, such as location. In this study, we found that the southern region showed the lowest score of performance related to inadequate infection control system inside the pharmacy and insufficient education and training during undergraduate and postgraduate levels. Furthermore, the worksite was another factor that affected the pharmacy infection control implementation. University and military healthcare organizations were the most practiced worksites where there was implementation infection control system. This result was expected because the university provides education and training on pharmacy infection control in a proper setting. Moreover, military hospitals have a very restricted system that prevents the transmission of infection among soldiers. Moreover, both of them should implement pharmacy infection control in practice in a healthcare setting. Age is an additional factor that affected the pharmacy infection control implementation, particularly pharmacists in the age group of 31-35 years with a work experience of $1-3$ years because the pharmacy staff was not in positions responsibilities for implementation pharmacy infection control program. In comparison, higher positions had the authority to implement the pharmacy infection control. However, only a single dependent factor positively affected $(26 \%)$ the implementation of pharmacy infection control, which was expected because the higher position has the authority to implement pharmacy infection control.

\section{Limitations}

The results of this study are informative with high-reliability data and acceptable sample size. Moreover, the demographic data of location and gender were equally distributed. However, there were some limitations to this study. For example, there was an unequal distribution of age, worksite, practice area, years of experience, and current position. In addition, there were not many studies to compare with them. Therefore, we recommend further studies with comparable demographic data.

\section{CONCLUSION}

The practice of pharmacy infection control by pharmacists in Saudi Arabia was found to be insufficient. Various factors might affect infection control practice, such as young age, low experience, and lower position. In addition, other factors such as geographic location, gender, worksite vary in the practice. Therefore, essential key performance indicators are highly suggested to improve the implementation of pharmacy infection control in Saudi Arabia.

\section{ACKNOWLEDGEMENT}

None.

\section{CONFLICT OF INTEREST}

The authors declare that there is no conflict of interest.

\section{Funding}

None

\section{Consent for Publications}

Informed consent was obtained from all the participants

\section{Ethical Approval}

This research is exempted from research and ethical committee or an institutional review board (IRB) approval.

https://www.hhs.gov/ohrp/regulations-andpolicy/decision-charts-2018/index.html

\section{ABBREVIATIONS}

MOH: Ministry of Health; KSA: Kingdom of Saudi Arabia; SPSS: Statistical package of social sciences; JASP: Jeffery's Amazing Statistics Program; STROBE: Strengthening the reporting of observational studies in epidemiology; VIF: Variance Inflation Factor.

\section{ORCID ID}

Yousef Ahmed Alomi (iD https://orcid. org/0000-0003-1381-628X

\section{REFERENCES}

1. Ontario Agency for Health Protection, Promotion, Provincial Infectious Diseases Advisory Committee. Best practices for infection prevention and control programs in all health care settings. Public health Ontario; 2012. 87 p.

2. Al Knawy B, Khoja T, Balkhy H, Pittet D. GCC Infection control manual; 2013. p. 1-324.

3. US Department of Health and Human Services. C for DC and P. Infection control in healthcare personnel: infrastructure and routine practices for occupational infection prevention and control services recommendations only [internet]; 2019. Available from: https://www.cdc.gov/ infectioncontrol/pdf/guidelines/infection-controlHCP-recommendations-only-H.pdf [cited 24/11/2021].

4. WESTON D. Fundamentals of Infection Prevention and Control Theory and practice [internet]. Wiley-Blackwell. p. 1-401; 2013. 2nd ed. Available from: https://books.google.com/ books?id=RhdRBqWpzmUC\&pgis=1 [cited 24/11/2021].

5. McGoldrick M. Infection prevention and control protocol, 2019. Vol. Home Healthc Nurse. 2019; Feb.

6. WHO. Practical guidelines for infection control in health care facilities. World Heal Organ. 2004;41:110.

7. Kastango ES, American Society of HealthSystem Pharmacists (ASHP). Blueprint for implementing USP chapter 797 for compounding sterile preparations. Am J Health Syst Pharm. 2005;62(12):1271-88. doi: 10.1093/ ajhp/62.12.1271, PMID 15947127.

8. Croteau D, Bock C, Hamilton R, Cohen D, Wilkinson D, Jacobson A, et al. Infection control for regulatory proffessionaessional, Pharmacists 'Edition; 2013.

9. Virox Technologies Inc. Infection prevention and control audit for pharmacy. Vol. 2090.

10. NHSGGC Infection Control Committee. Infection control guidelines for community pharmacy; 2019.

11. Alomi YA, Alyousef AM. Infection control pharmacist: A new initiative project in the Kingdom of Saudi Arabia. PTB Reports. 2021;7(2):40-3. doi: 10.5530/PTB.2021.7.8.

12. Alomi YA, Abdullah Hakami LE, Yahya Khayat NA, Bamagaus YA, Rafuden Bakhsh TM, Adnan Khayat $\mathrm{N}$, et al. Mass gathering (hajj) pharmacy infection control: new initiative in Saudi Arabia. IJPCS. 2020;9(1):5-9. doi: 10.5530/ijpcs.2020.9.2.

13. Tauman AV, Robicsek A, Roberson J, Boyce JM Healthcare-associated infection prevention and control: pharmacists' role in meeting national patient safety goal 7. Hosp Pharm. 2009;44(5):401-11. doi: 10.1310/hpj4405-401.

14. Murtough SM, Hiom SJ, Palmer M, Russell AD. A survey of rotational use of biocides in hospital pharmacy aseptic units. J Hosp Infect. 2002 Mar;50(3):228-31. doi: 10.1053/jhin.2001.1155, PMID 11886201.

15. Sum ZZ, OW CJW. Community pharmacy response to infection control during COVID-19. A cross-sectional survey. Res Social Adm Pharm. 2021;17(1):1845-52. doi: 10.1016/j. sapharm.2020.06.014, PMID 33317763

16. Adegboye MB, Zakari S, Ahmed BA, Olufemi GH Knowledge, awareness and practice of infection control by health care workers in the intensive care units of a tertiary hospital in Nigeria. Afr Health Sci. 2018 Mar 1;18(1):72-8. doi: 10.4314/ 
ahs.v18i1.11, PMID 29977260.

17. Charan J, Biswas T. How to calculate sample size for different study designs in medical research? Indian J Psychol Med. 2013;35(2):121-6. doi: 10.4103/0253-7176.116232, PMID 24049221.

18. Pourhoseingholi MA, Vahedi M, Rahimzadeh M. Sample size calculation in medical studies. Gastroenterol Hepatol Bed Bench. 2013;6(1):14-7. PMID 24834239.

19. Ezhumalai DG. How Big A Sample Do I Require?. Annals of SBV. 2017;6(1):39-41. doi: 10.5005/jpjournals-10085-6113.

20. Johnson TP, Wislar JS. Response rates and nonresponse errors in surveys [internet]. JAMA. 2012;307(17):1805-6. doi: 10.1001/ jama.2012.3532, PMID 22550194.

21. Von Elm E, Altman DG, Egger M, Pocock SJ, Gøtzsche PC, Vandenbroucke JP. The strengthening the reporting of observational studies in epidemiology (STROBE) statement: guidelines for reporting observational studies.
PLOS Med. 2007;4(10):1623-7. doi: 10.1371/ journal.pmed.0040296.

22. Von Elm E, Altman DG, Egger M, Pocock SJ, Gøtzsche PC, Vandenbroucke JP. The Strengthening the Reporting of Observational Studies in Epidemiology (STROBE) statement: guidelines for reporting observational studies [internet]. Vol. 370; 2007. Available from: http:// www.thelancet.com. Available from: http://www. plosmedicine.org [cited 24/11/2021].

23. Langan SM, Schmidt SA, Wing K, Ehrenstein $V$, Nicholls SG, Filion KB, et al. The reporting of studies conducted using observational routinely collected health data statement for pharmacoepidemiology (RECORD-PE). BMJ. 2018;363:k3532. doi: 10.1136/bmj.k3532, PMID 30429167.

24. Liao D, Valliant R. Variance inflation factors in the analysis of complex survey data. Surv Methodol. 2012;38(1):53-62.

25. Akinwande MO, Dikko HG Samson A. Variance inflation factor: As a condition for the inclusion of suppressor variable(s) in regression analysis.
Open J Stat. 2015;05(7):754-67. doi: 10.4236/ ojs.2015.57075.

26. Thompson CG, Kim RS, Aloe AM, Becker BJ. Extracting the Variance Inflation Factor and Other Multicollinearity Diagnostics from Typical Regression Results. Basic Appl Soc Psych. 2017;39(2):81-90. doi: 10.1080/01973533.2016.1277529.

27. United States Pharmacopeia, General Chapter USP <800> Hazardous Drugs- Handling in Healthcare Settings. The United States pharmacopeial convention. 2017. p. 1-20.

28. USP, General Chapter USP < 795> Pharmaceutical Compounding - Nonsterile Preparations. USP 42 NF [internet]. p. 1-13; 2019. Available from: http:// www.usp.org/compounding/general-chapter-795 [cited 24/11/2021]. In:.

29. United States Pharmacopia. USP General Chapter $<825>$ radiopharmaceuticals - preparation compounding, dispensing, and repackaging United States Pharmacopia. 2019:1-29://www. 